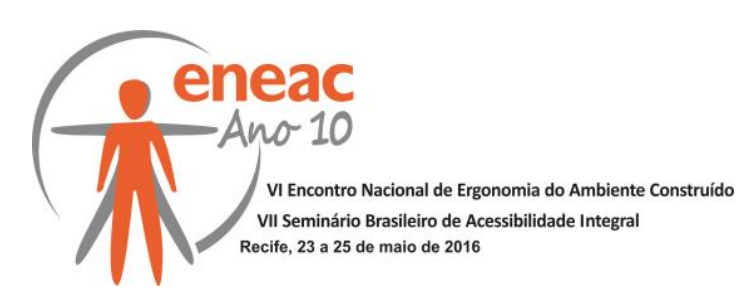

\title{
O BANHEIRO ACESSÍVEL SOB O OLHAR DO USUÁRIO
}

\author{
DE LIMA, Mariana Azevêdo (1); \\ ELALI, Gleice Azambuja (2). \\ (1) ) UFRN, Mestranda em Arquitetura e Urbanismo \\ e-mail:marianna azevedo@hotmail.com.br \\ (2) UFRN, Doutora em Arquitetura e Urbanismo \\ e-mail: gleiceae@gmail.com
}

\begin{abstract}
RESUMO
Este artigo investiga como usuários percebem banheiros executados em conformidade com a NBR 9050/04, de modo a indicar se tais ambientes são realmente inclusivos. Ele constitui um recorte de pesquisa de mestrado em andamento no PPGAU/UFRN, cuja meta é compreender como a NBR se relaciona com os princípios de Design Universal. A pesquisa de campo recorreu à realização de tarefas acompanhadas - método inspirado no 'passeio acompanhado' (DISCHINGER, 2000; RHEINGANTZ, 2009). O artigo apresenta os resultados da realização dessas atividades com três participantes (dentre os nove que integrarão a dissertação em andamento): pessoa com cegueira total, grávida e pessoa ostomizada.
\end{abstract}

Palavras-chave: NBR 9050; banheiro; usuário.

\begin{abstract}
This paper investigates how users perceive bathrooms executed in accordance with NBR 9050/04 in order to indicate whether such environments are inclusive. It is a master's research in progress in PPGAU/UFRN, whose goal is to understand how the NBR relates to the principles of Universal Design. The field research resorted to accompanied tasks - a method inspired by the 'accompanied walk' (DISCHINGER, 2000; RHEINGANTZ, 2009). The article presents the results of these activities with three participants (among the nine that will compose the dissertation in progress): a vision impairment person, a pregnant and an ostomate person.
\end{abstract}

Keywords: NBR 9050; restroom; user.

\section{INTRODUÇÃO}

Alinhado com a tendência mundial, nos últimos trinta anos o Brasil tem vivenciado notório avanço no tratamento do tema acessibilidade. As discussões, iniciadas na década de 1980 com a promulgação da "Constituição Cidadã" (BRASIL, 1988) e a publicação da primeira norma técnica sobre o tema pela Associação Brasileira de Normas Técnicas (ABNT) - a NBR 9050: Adequação das Edificações e do Mobiliário Urbano à Pessoa Deficiente, datada de 1985 e modificada em 1994, 2004 e 2015 -, progrediram até alcançar o conceito mais amplo do Design Universal como "o design de produtos e ambientes para serem utilizados 


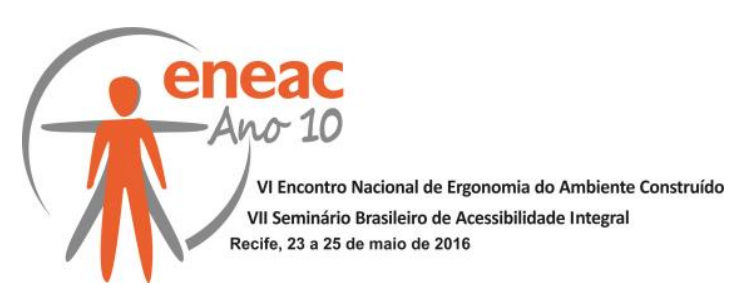

por todas as pessoas, na maior extensão possível, sem a necessidade de adaptação ou solução especializada" (MACE, 1985, apud STEINFELD; MAISEL, 2012, p. 28)'.

Porém, mesmo com a existência de um conceito já consolidado de Design Universal no país, a prática profissional da pesquisadora - que consiste em trabalhos de fiscalização desenvolvidos junto ao Ministério Público do Rio Grande do Norte (MPRN) em edificações de uso público e coletivo -, mostra que existem muitas situações que não atendem às necessidades de todos os usuários das edificações. Em várias vistorias é evidente 0 cumprimento às obrigações normativas, porém realizado de maneira tão literal que acaba promovendo soluções segregadoras, o que inviabiliza a produção de espaços de bem-estar e inclusão social. Dentre essas situações se destacam: (i) o atendimento à exigência de uma entrada acessível com a sua oferta em local distante da entrada principal, nas fachadas laterais ou nos fundos da edificação; (ii) o respeito a exigência de uma porcentagem de mesas acessíveis em restaurantes, porém em áreas específicas, ao invés de uma distribuição uniforme ou até mesmo $100 \%$ de adequação do mobiliário; (iii) surgimento de ambientes acessíveis a grupos específicos de usuários e que segregam outros grupos como, por exemplo, o banheiro acessível separado dos demais boxes.

\section{Dessa reflexão surgiu a pergunta de partida que conduziu o estudo: "As exigências da NBR 9050 em relação a banheiros públicos respondem às necessidades dos diversos possíveis usuários desse ambiente?"}

É importante esclarecer que, neste texto, o termo "banheiro público" corresponde a banheiros localizados em edifícios de uso público ${ }^{2}$ ou de uso coletivo ${ }^{3}$, o que exclui banheiros residenciais, os quais não têm obrigatoriedade de serem acessíveis. $O$ banheiro público foi tomado como estudo de caso devido à: (i) sua importância na satisfação de necessidades básicas e na manutenção da dignidade da pessoa humana, que não podem ser alcançadas caso não haja a garantia de autonomia, privacidade e usabilidade na interação usuário-ambiente; (ii) ser um ambiente exigido em instituições públicas e privadas (prestadoras de serviço ou comerciais) e que, portanto, deve estar disponível para utilização por qualquer cidadão.

A opção pela limitação do estudo a uma unidade espacial da edificação permite trabalhar com um nível maior de detalhamento e variação de conformações espaciais. Além disso, desde sua versão inicial, a NBR 9050 traz parâmetros relativos à acessibilidade do ambiente banheiro e das peças sanitárias (lavatório, bacia sanitária e chuveiro), fornecendo considerável número de elementos para análise.

\section{MÉTODO}

Para selecionar os ambientes objetos de estudo foram visitados dez banheiros adaptados com diferentes conformações espaciais e ofertas de funcionalidades (por ex.: com e sem chuveiro) situados em prédios de uso público ou uso coletivo na cidade de Natal/RN. Eles foram avaliados pela aplicação do protocolo para avaliação da acessibilidade, conforme padrão utilizado pelo MPRN, o qual leva em consideração os aspectos elencados na NBR 9050/04. Dentre os banheiros analisados, os dois que mais se aproximaram do atendimento integral à norma foram selecionados para continuidade da pesquisa.

\footnotetext{
1 Tradução livre da autora, do original em inglês: "The design of products and environments to be usable by all people, to the greatest extent possible, without the need for adaptation or specialized design".

2 VI - edificações de uso público: aquelas administradas por entidades da administração pública, direta e indireta, ou por empresas prestadoras de serviços públicos e destinadas ao público em geral. (BRASIL, 2004)

3 VII - edificações de uso coletivo: aquelas destinadas às atividades de natureza comercial, hoteleira, cultural, esportiva, financeira, turística, recreativa, social, religiosa, educacional, industrial e de saúde, inclusive as edificações de prestação de serviços de atividades da mesma natureza. (BRASIL, 2004)
} 


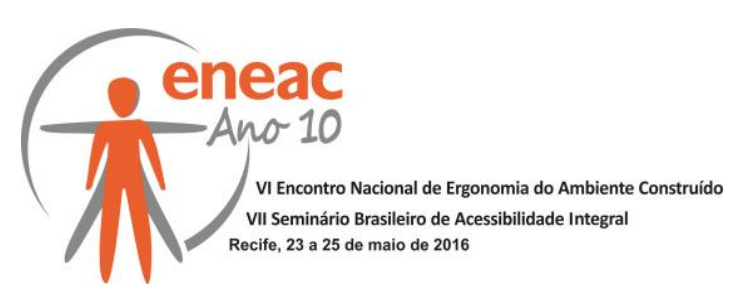

O banheiro A se localiza em uma arena multiuso e oferta lavatório, bacia sanitária, chuveiro e uma superfície para troca de roupas na posição deitada (Figura 1). Dentre os 62 itens analisados no protocolo, apenas três $(4,8 \%)$ não estão de acordo com as exigências normativas.

O banheiro B se localiza em hotel no bairro de Ponta Negra, região turística da cidade. Em seu espaço interno, possui lavatório, bacia sanitária e chuveiro (Figura 2). Encontra-se na área interna de um dos apartamentos adaptados do estabelecimento. Nesse caso, o ambiente atendeu $100 \%$ dos itens analisados.

Figura 1. Planta baixa do banheiro A

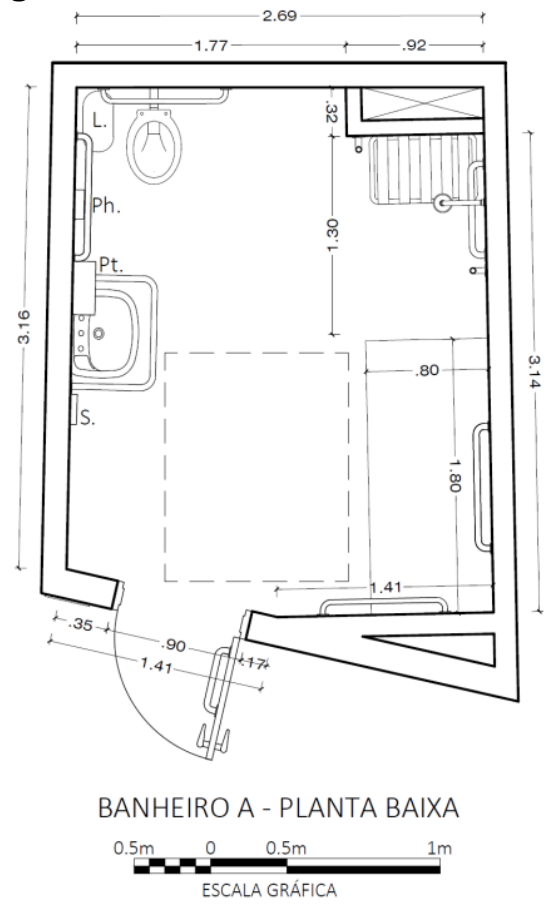

Fonte: Produção da autora, 2015.
Figura 2. Planta baixa do banheiro B

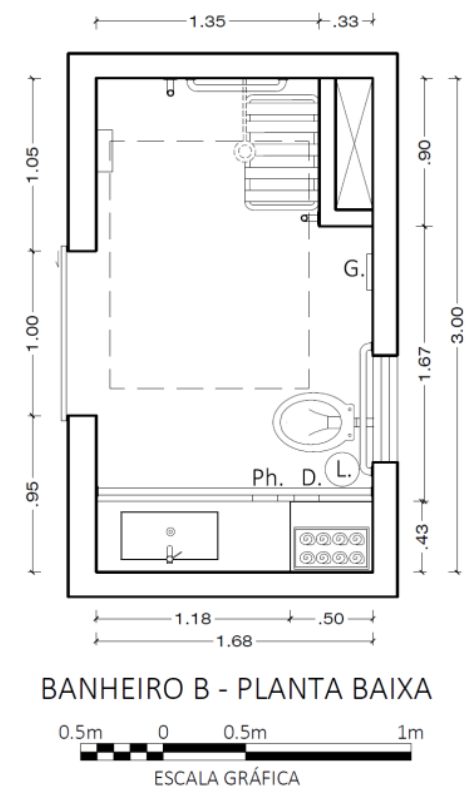

Fonte: Produção da autora, 2015.

Ressalte-se que desde 11 de outubro de 2015 uma nova versão da NBR 9050 passou a vigorar com alterações consequentes de processo de revisão. No entanto, decidiu-se continuar a pesquisa que estava em andamento considerando os banheiros selecionados em conformidade com a versão de 2004 uma vez que: (i) dada a recente alteração normativa, ainda não existem banheiros em total conformidade com a nova norma; (ii) os banheiros selecionados estão de acordo com a maioria das novas exigências, diferindo apenas em relação a: localização da barra do lavatório, inexistência de barra vertical ao lado da bacia sanitária e localização de ralo dentro das áreas de manobra/transferência.

Em relação ao método utilizado, optou-se pela realização de tarefas acompanhadas, atividade inspirada no passeio acompanhado - um tipo de entrevista que conjuga uma visita ao espaço a uma conversa informal de modo a avaliar a percepção dos usuários com relação a diversos aspectos do ambiente (DISCHINGER, 2000; RHEINGANTZ, 2009). Assim, ao longo da visita foi solicitado que os participantes realizassem tarefas previamente definidas como, por exemplo, lavar as mãos e simular a utilização da bacia sanitária enquanto descreviam a sua experiência no ambiente em relação à acessibilidade.

Durante a realização das tarefas, foram feitas perguntas genéricas que permitiram à pesquisadora apreender a sua percepção do ambiente, conforme sugerido por Brill et al. (1985, p. 243 apud RHEINGANTZ et al., 2009). Além de uma breve caracterização do usuário, o guia de entrevista continha questões sobre pontos positivos e negativos relativos 


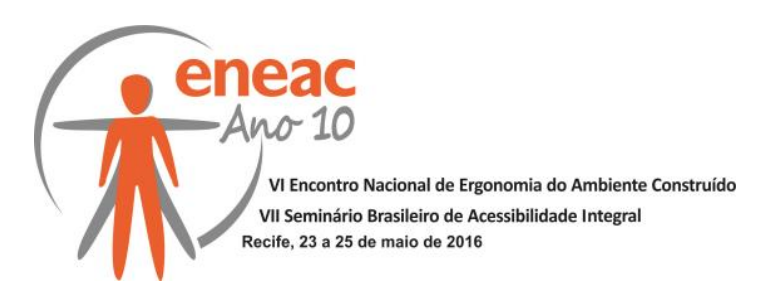

à: entrada (sinalização, maçaneta, largura da porta, barra), termos construtivos (ex: iluminação, revestimentos etc.), uso do lavatório (aproximação, barra de apoio, comando, saboneteira, papeleira, espelho, ganchos para acessórios, prateleira), uso do vaso sanitário (altura, barras, ducha, papeleira, descarga, lixeiro), uso do chuveiro (comando, banco, barras) e uso da superfície para troca de roupas. Além disso questionava-se o que deve ser mantido como está, o que deve ser modificado, e qual dos dois banheiros considera mais adequado às suas necessidades.

As atividades foram registradas em vídeo e anotações relativas à observação detalhada acerca da maneira como eles se deslocam e utilizam o ambiente. Os dados obtidos foram transcritos e analisados de maneira qualitativa.

Para a pesquisa em andamento, o recrutamento dos participantes englobou nove pessoas com perfis diferentes: em cadeira de rodas, com deficiência visual, ostomizado, muletante, idoso, obeso, anão, grávida e um indivíduo sem restrição de mobilidade. Neste artigo serão apresentados os resultados dos experimentos realizados até o momento, com três participantes, os quais são identificados por códigos, colocados entre parênteses, que expressam "tipo de restrição-sexo-idade":

- Pessoa com deficiência visual (PDV-M-34), sexo masculino, 34 anos, caso de cegueira total adquirida em decorrência de atropelamento ocorrido em 2003;

- Grávida (G-F-29), 29 anos, com sete meses e meio de gestação na data de realização do experimento;

- Pessoa ostomizada (POst-M-65), sexo masculino, 65 anos, com ostomia adquirida devido à retirada de grande parte do intestino delgado em 2003, após descoberta de polipose familiar.

\section{RESULTADOS}

\subsection{Banheiro A}

A pessoa com deficiência visual considerou como aspectos positivos a largura da porta e a abertura de giro, considerados de fácil entendimento. Entretanto, a placa tátil ao lado da porta foi considerada muito baixa para o toque das mãos e leitura. Quando questionado acerca de aspectos construtivos, considerou o piso liso e demonstrou receio quanto à ocorrência de acidentes. PDV-M-34 relatou como ponto positivo no lavatório a existência de sabonete líquido fixado na parede e não apoiado sobre a bancada. Ele mencionou que, ao procurar o sabonete tateando superfícies com vários objetos, às vezes acaba derrubando algo (Figura 3). Observou também a colocação da papeleira do lado direito como aspecto positivo, já que, por ser destro, é sempre o primeiro lado que tateia. Apesar de não mencionar, PDV-M-34 teve dificuldades para secar as mãos - já que o dispositivo de papel liberava uma única folha por vez, a qual se desmanchava ao ser puxada por mãos molhadas - e para encontrar o lixeiro - já que só existia um no ambiente, próximo ao sanitário. Em relação ao uso da bacia sanitária, o usuário considerou a altura do assento baixa e relatou também como ponto negativo a localização do papel higiênico (Figura 4), já que no banheiro B ele estava mais baixo e do lado esquerdo de quem está sentado no sanitário ("Por que em cada banheiro há uma altura e localização diferente para o papel?"). Caso houvesse um padrão mais rígido para localização dos elementos, a utilização do espaço seria bastante facilitada, já que ao entrar em um banheiro acessível ele já saberia a localização exata de todos os itens. Em relação à área de banho, apontou como ponto positivo o comando de giro, considerado por ele como padrão, portanto de fácil entendimento quanto ao seu funcionamento. No entanto, afirmou que deveria ser instalado suporte (prateleira) para 


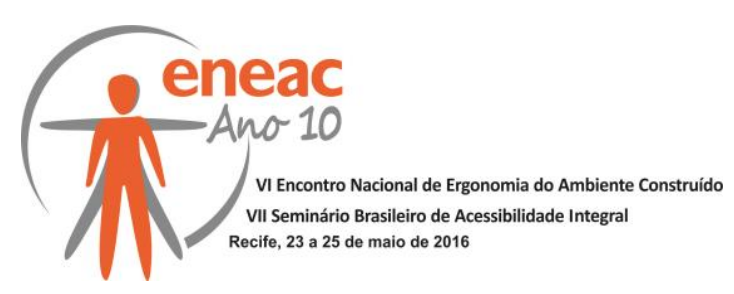

colocação de sabonete, shampoo e qualquer outro material necessário para o banho. A superfície para troca de roupas foi classificada como adequada ao uso, já que seria utilizada apenas para apoiar algum objeto. Por fim, afirmou que apenas o lavatório deveria ser mantido como está.

Figura 3. PDV - Reconhecimento da superfície do lavatório antes da utilização

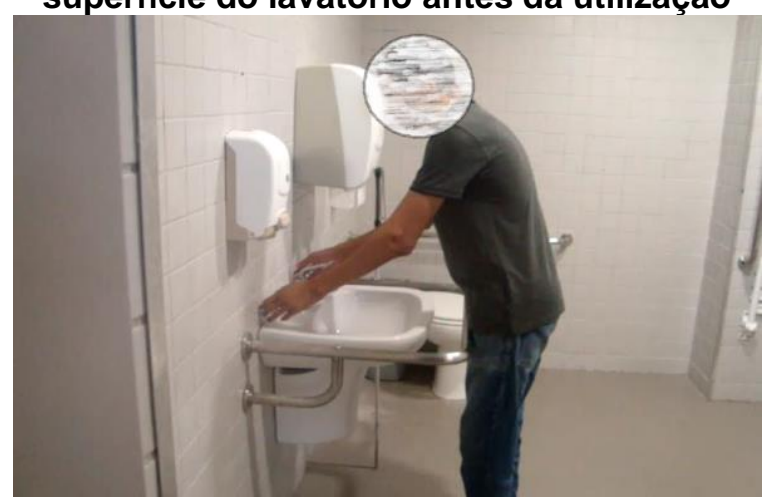

Fonte: Acervo próprio, 2015.
Figura 4. PDV - Papel higiênico sem localização padronizada

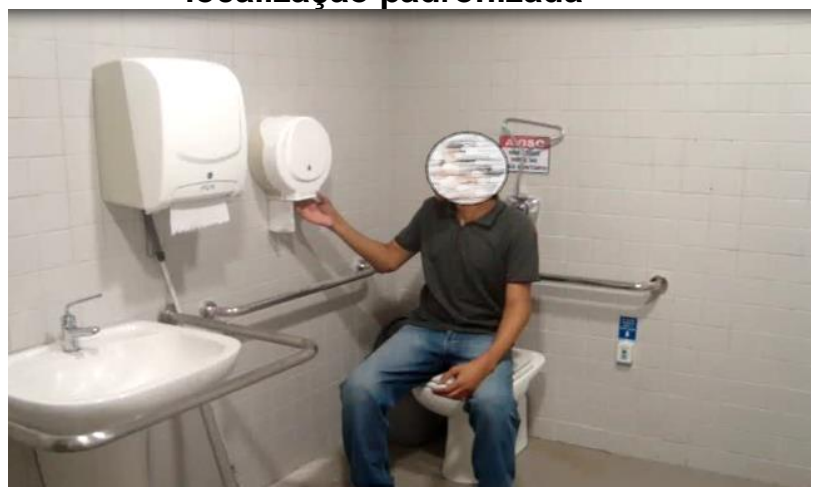

Fonte: Acervo próprio, 2015.

A pessoa ostomizada considerou o ambiente adequado às suas necessidades no que se refere a termos construtivos, lavatório e área de banho. Em relação ao uso da bacia sanitária, relatou como ponto positivo a proximidade do lavatório e a existência de dois suportes de papéis (papel higiênico e papel toalha) muito próximos ao vaso, os quais podem ser utilizados para secar a bolsa após a higienização conforme a preferência do usuário. Mencionou ainda que o lado direito do vaso é melhor para o posicionamento de ducha e papéis, já que a maioria das ostomias é do lado esquerdo do corpo e o esvaziamento e limpeza da bolsa são feitos em pé, em frente à peça sanitária (Figura 5). No entanto, considerou a altura do assento baixa ("Em relação ao vaso, quando mais você puder subir, melhor") e criticou enfaticamente a ausência de ducha higiênica. Ele mencionou que quando não existe ducha próximo ao vaso, faz-se necessário levar para dentro do banheiro garrafa ou copo com água para lavar a bolsa. Quando questionado acerca da conformidade da superfície para troca de roupas, não manifestou nenhuma opinião, declarando apenas que não a utilizaria. Por fim, afirmou que tudo poderia ser mantido como está, com exceção de um ponto: "A única diferença [desse banheiro para um ideal para ostomizados] é que o vaso seria como se fosse uma pia (Figura 6)".

Figura 5. POst - Simulação da utilização da bacia sanitária para esvaziamento da bolsa.

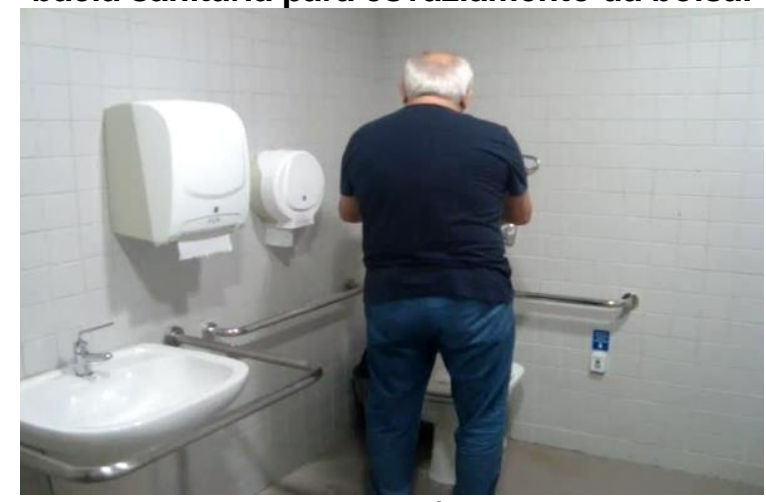

Fonte: Acervo próprio, 2015.
Figura 6. POst - Demonstração da altura ideal para o sanitário, igual a do lavatório.

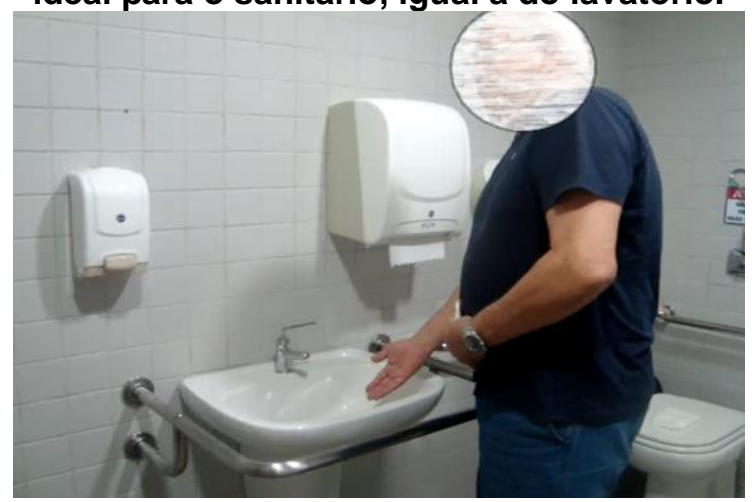

Fonte: Acervo próprio, 2015. 


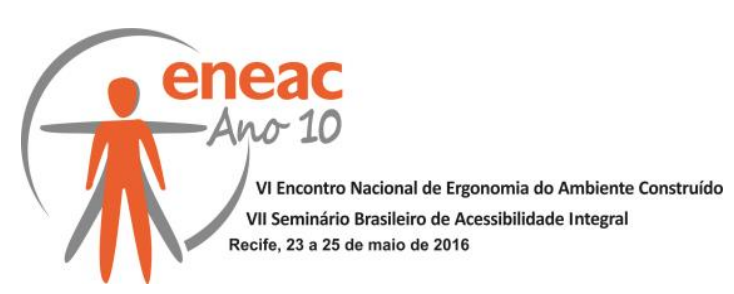

Em relação à entrada, a grávida considerou a porta um pouco pesada, exigindo força considerável para a abertura. Quando questionada acerca dos pontos positivos e negativos do ambiente em termos construtivos, a usuária relatou que o ambiente não é agradável esteticamente, já que não existe nenhum tratamento diferenciado em relação às superfícies ("Com certeza modificaria a questão do revestimento e da qualidade estética do ambiente, que deixam muito a desejar").

No que se refere ao lavatório, considerou a aproximação difícil devido à existência de barra na frente da peça avançando bastante em relação a ela (Figura 7). $O$ tipo de comando da torneira não foi compreendido facilmente: a usuária não entendeu se deveria levantar ou abaixar a alavanca para liberar a água e ficou em dúvida se a corrente cessaria automaticamente ou se seria necessário acionar o comando novamente para desligá-lo ("Não entendi se ele fecha sozinho. Não dá pra identificar. Não entendi se aperta pra cima ou aperta pra baixo").

Em relação ao uso da bacia sanitária, a usuária considerou como ponto positivo a localização da barra lateral à direita de quem está sentado (Figura 8). Explicou ainda que isso se deve ao fato de ela ser destra e considerar a empunhadura mais firme desse lado. No entanto, afirmou não compreender como ocorre o uso da alavanca de acionamento da descarga (Figura 9).

Ao simular a tarefa do banho, a usuária sentiu insegurança com o ralo no centro do boxe: "Pra uma pessoa que não vai usar a cadeira de banho, é super inconveniente ficar pisando nesse ralo. [...] A pessoa fica insegura de tomar banho em cima desse ralo, principalmente eu que estou mais pesada. Se eu pisar aí, e o ralo entrar?". Comentou ainda que o fato de não haver desnível na área do banho acaba por molhar todo o ambiente quando o chuveiro sendo utilizado (Figura 10). Ao perceber a existência da superfície para troca de roupas, considerou-a bem interessante para apoiar algum objeto na ausência de ganchos ou prateleiras, bem como para calçar sapatos ou vestir algumas peças de roupa como calças, já que a gravidez interfere um pouco no equilíbrio corporal.

Quando questionada sobre o que deveria ser mantido como está, elencou a sinalização da porta, a oferta de um espaço que permita ao usuário sentar-se para a troca de roupas, a barra lateral e o lixeiro do lado direito da pessoa que utiliza a bacia sanitária.

Ao final da realização das tarefas, apontou como ponto bastante negativo o fato de existir apenas um banheiro para ambos os sexos. Segundo ela, "você já não se sente à vontade de sentar num sanitário de banheiro público; muito menos sendo unissex" e no caso da grávida, utilizar o vaso sem sentar "é mais complicado, porque você tem um peso a mais e tem ainda a questão do equilíbrio, que fica dificultado".
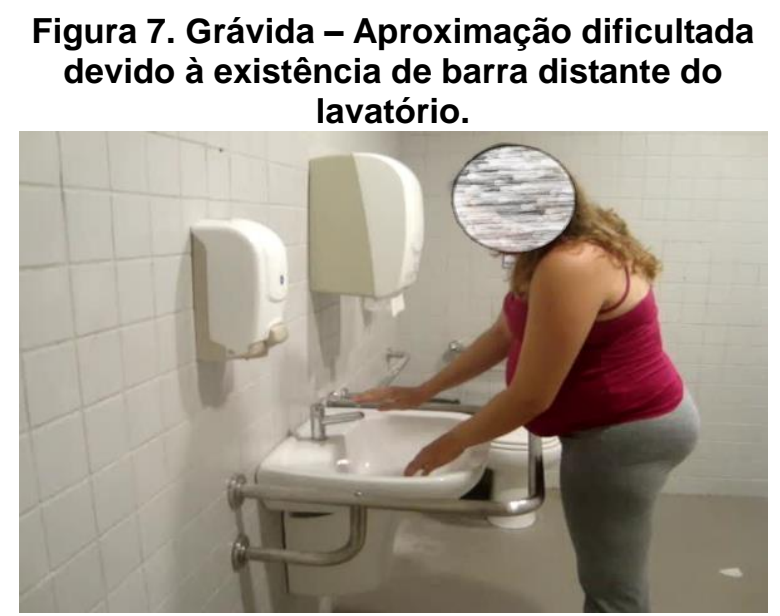

Fonte: Acervo próprio, 2015.

\section{Figura 8. Grávida - Boa localização da barra lateral, ao lado direito.}

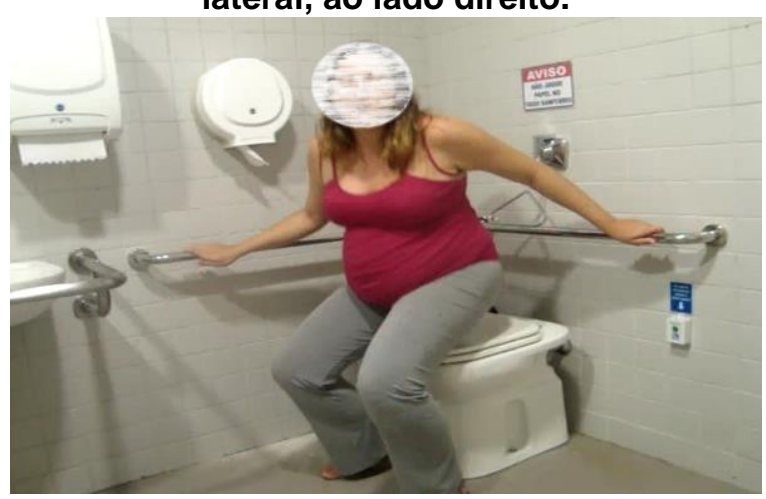

Fonte: Acervo próprio, 2015. 


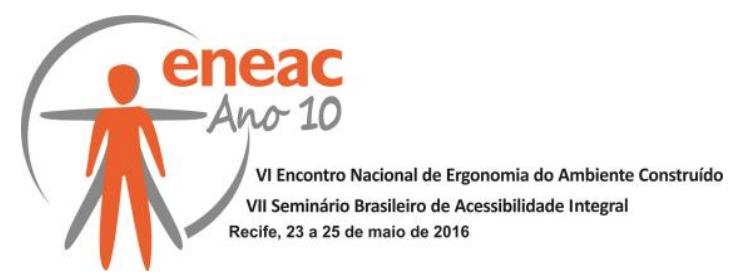

Figura 9. Grávida - Difícil compreensão do funcionamento da descarga.

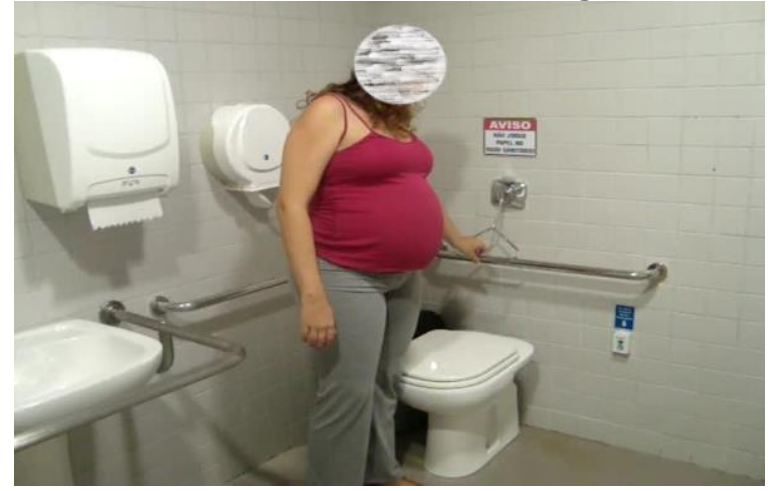

Fonte: Acervo próprio, 2015.
Figura 10. Grávida - Insegurança causada pela localização do ralo.

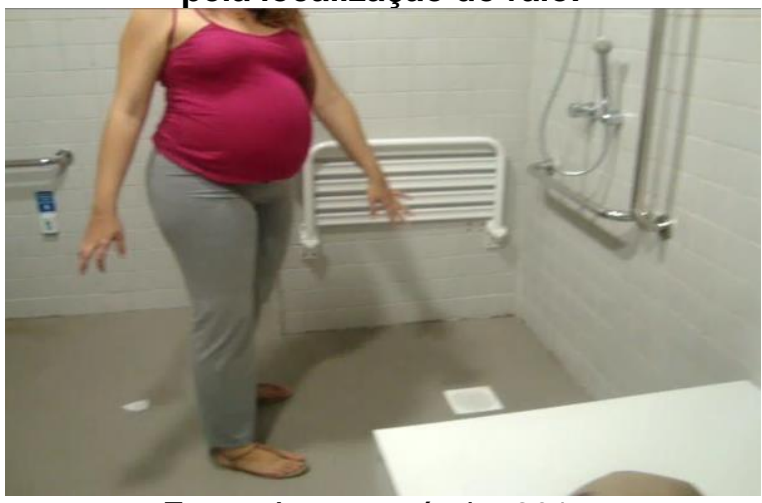

Fonte: Acervo próprio, 2015.

Os esquemas representativos das áreas percebidas como positivas e negativas pelos usuários do banheiro A se apresentam da seguinte maneira (Figura 11 a Figura 13):
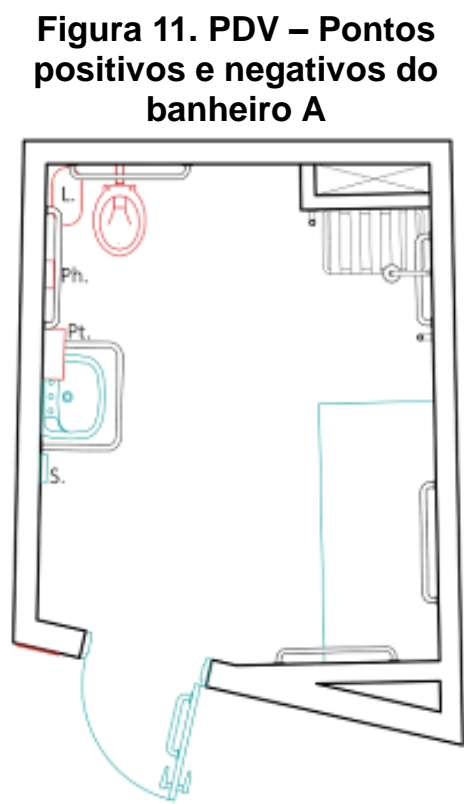

BANHEIRO A - PLANTA BAIXA

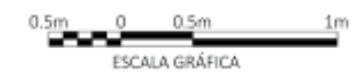

ISGENDA: PONTOS POSITTUOS / PONTOS NEGATINOS

Fonte: Produção da autora, 2015.
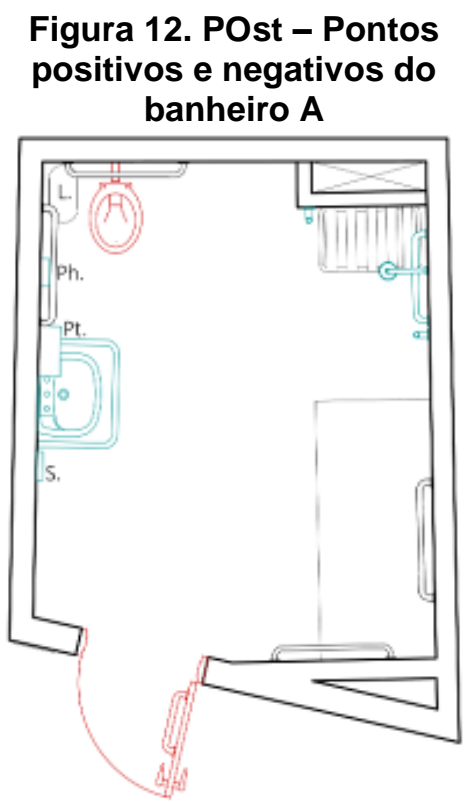

BANHEIRO A - PLANTA BAIXA

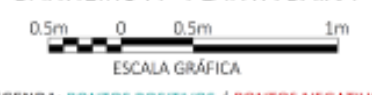

EGENDA: PONTOS POSITNDS / PONTOS NEGATINOS

Fonte: Produção da autora, 2015.
Figura 13. Grávida - Pontos
positivos e negativos do banheiro A

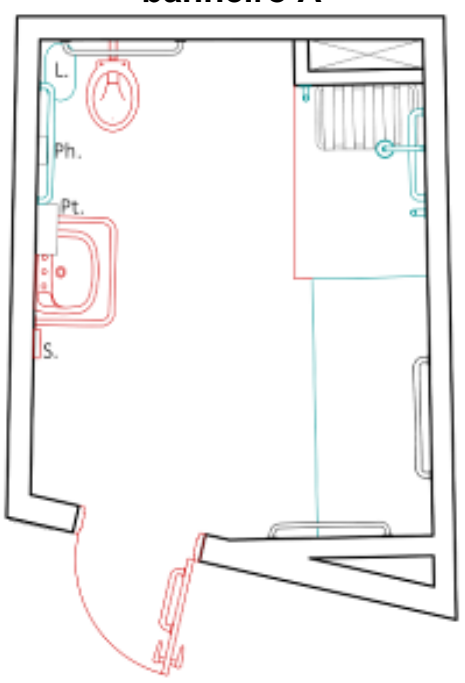

BANHEIRO A - PLANTA BAIXA

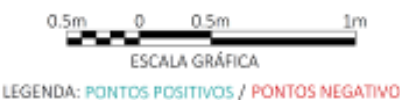

Fonte: Produção da autora, 2015.

\subsection{Banheiro B}

A pessoa com deficiência visual considerou a largura da porta como aspecto positivo. Entretanto, teve dificuldades para entender o mecanismo de abertura (de correr): tentou empurrar e puxar e, por fim, perguntou como ela deveria ser aberta (Figura 14). Diante do esclarecimento da pesquisadora, sugeriu a implantação de sinalização indicando a forma de manuseio. No que se refere a aspectos construtivos, o piso foi considerado confortável e seguro devido a sua característica antiderrapante ("Esse piso é interessante pra a gente [pessoas com deficiência visual] porque se estiver molhado não corremos o risco de 


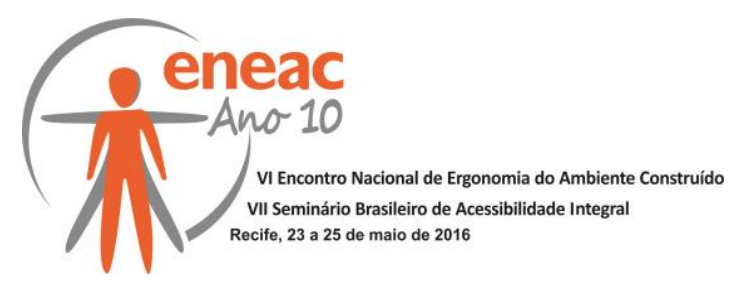

escorregar"). Ao realizar a tarefa de lavar as mãos, relatou a altura da bancada e a inexistência de sabonete líquido como pontos desfavoráveis ("Não sei o padrão de altura do lavatório, mas pra mim está muito baixo"). Além disso, a existência de vários itens na bancada (como copos e shampoos) dificultou a identificação do sabonete em barra e das toalhas. Mencionou ainda que a localização desses itens no lado esquerdo da cuba dificulta a identificação já que, por ser destro, o lado direito é sempre o primeiro que tateia, e que se os objetos estivessem sempre do mesmo lado facilitaria bastante ("Quando a gente chega em algum ambiente, tá no lado direito; quando chega em outro, tá no lado esquerdo, e a gente fica procurando. Aí quando pensa que não, bate e derruba, acontece de alguma coisa cair no chão e lá vai a gente se abaixar, procurar e não acha"). Em relação ao uso da bacia sanitária, o usuário considerou a altura do assento baixa. Além disso, criticou a localização da ducha e da papeleira do lado esquerdo de quem está sentado no vaso (Figura 15). Apesar de não mencionar, percebeu-se que ao tatear os objetos, PDV-M-34 quase derrubou os rolos de papel higiênico devido ao fato de estarem em suporte móvel, e não fixos na parede. Ao simular a realização da tarefa de tomar banho, apontou como pontos negativos a localização da prateleira distante da área de banho e o comando misto de alavanca/giro, já que não compreendeu o seu funcionamento, sendo necessário solicitar auxílio para utilização. Mencionou ainda que o comando de giro permitiria compreensão imediata. Quando questionado acerca do que manteria no banheiro, afirmou que a rugosidade do piso e a largura da porta, já que foram os únicos itens sem pontos negativos.

Figura 14. PDV - Porta com abertura de difícil compreensão

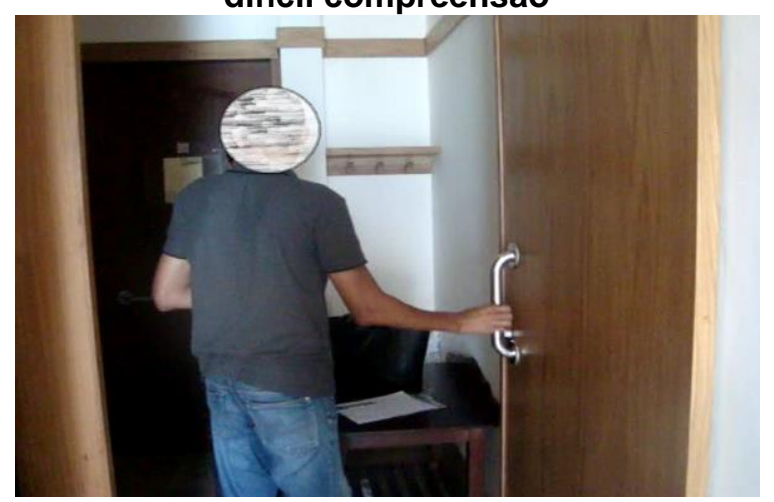

Fonte: Acervo próprio, 2015.
Figura 15. PDV - Localização inadequada da ducha e do papel higiênico

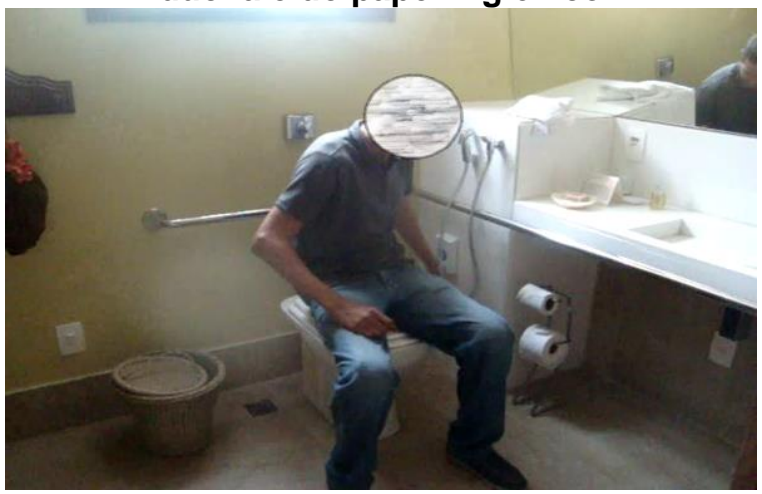

Fonte: Acervo próprio, 2015.

A pessoa ostomizada considerou o ambiente adequado às suas necessidades no que se refere à entrada, aspectos construtivos e área de banho. Após a atividade de lavar as mãos o usuário procurou papel toalha na parede do seu lado direito. Após terem sido mostradas as toalhas existentes na extremidade esquerda da bancada, ele continuou a apontar o lado direito, mais próximo, como o local mais adequado (Figura 16). Em relação ao uso da bacia sanitária, o usuário considerou a altura do assento baixa, relatando que na hora de esvaziar a bolsa, o conteúdo pode sujar a sua roupa ao bater na água. Para reduzir esse risco, ele informou que costuma se abaixar e esvaziar a bolsa simultaneamente ao acionamento da descarga (Figura 17). O usuário demonstrou ainda como procede a higienização da bolsa coletora, ainda no sanitário, com a ducha higiênica, a qual desempenha função essencial em suas atividades diárias. POst-M-65 sentiu falta ainda de papel toalha ("mais grosso") próximo ao vaso para secar a bolsa, já que o papel higiênico se desfaz facilmente em contato com a água. Quando questionado acerca do que deveria ser mantido como se encontra, afirmou que tudo, com exceção do vaso sanitário, que deveria ser na altura da bancada do lavatório, fornecendo a mesma resposta dada em relação ao banheiro $A$. 


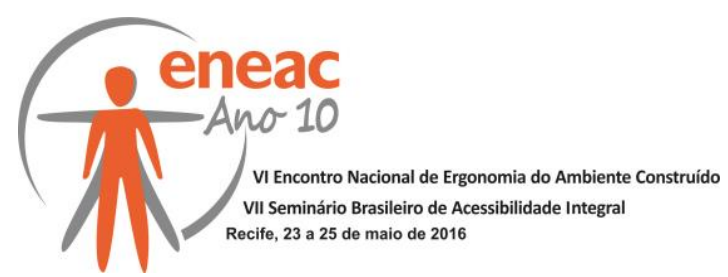

Figura 16. POst - Indicação do lado direito como mais apropriado para localização de papel ou toalha

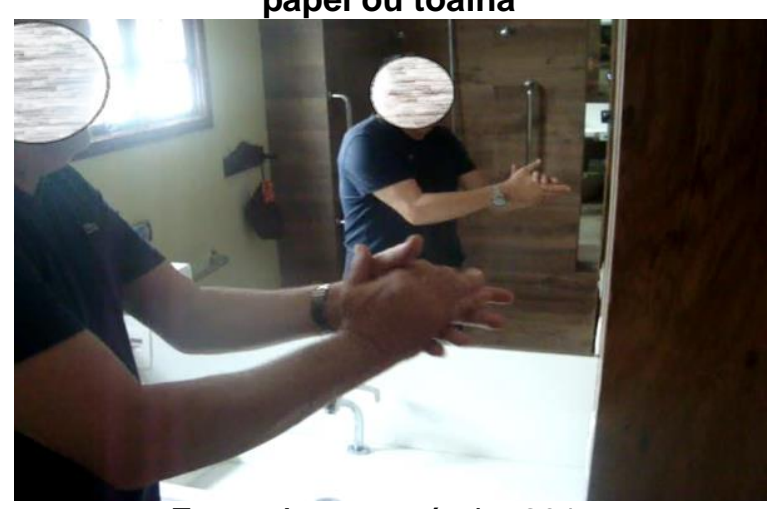

Fonte: Acervo próprio, 2015.
Figura 17. POst - Demonstração da necessidade de se abaixar devido à altura reduzida do vaso

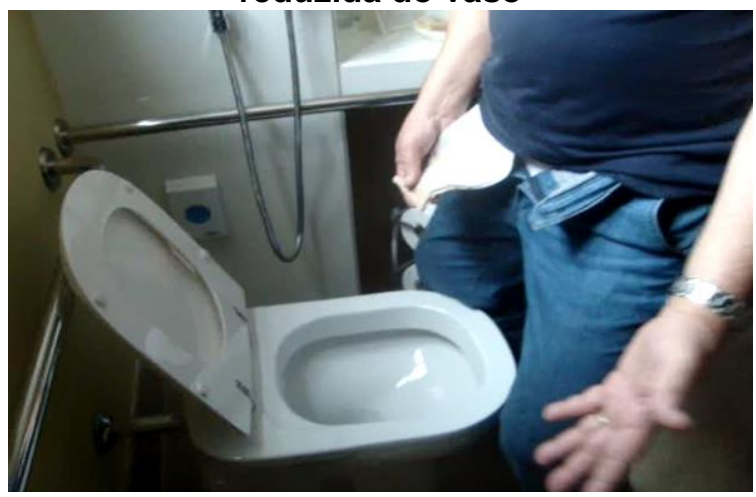

Fonte: Acervo próprio, 2015.

A grávida considerou a entrada do banheiro B adequada ao uso ("A porta é bem leve e os tamanhos da abertura e da maçaneta são ótimos") e, quando questionada acerca dos pontos positivos e negativos em termos construtivos, observou a boa distribuição das peças sanitárias no espaço. Ao entrar no ambiente, a usuária comentou que a primeira coisa que procura é um gancho para pendurar a bolsa, portanto observou a existência do acessório como ponto positivo no banheiro analisado. Ao iniciar a atividade de lavar as mãos, comentou que o lavatório é um pouco baixo, porém não chega a ser desconfortável para sua utilização, e que poderia haver um gancho com toalhas do lado direito, contrário ao lado onde elas estão (Figura 18). Em relação ao uso da bacia sanitária, a usuária considerou como ponto negativo a localização da ducha e da barra de apoio do lado esquerdo de quem está sentado ("Pra mim particularmente, que sou destra, se a ducha estivesse desse outro lado seria melhor [...] A mesma coisa pra a barra. Se tivesse barra desse outro lado, que é o meu lado de apoio, talvez eu até utilizasse"). Quando solicitada a simular a tarefa de banho, considerou a área adequada para este fim. Comentou somente que o fato de não haver desnível na área do banho acaba por molhar todo o ambiente quando o chuveiro está sendo utilizado ("Eu molharia tudo. Pra mim, como eu não tenho muitas dificuldades de locomoção, se esse espaço tivesse piso rebaixado ou blindex seria melhor") (Figura 19). Quando questionada sobre o que deveria ser mantido como está, a usuária demonstrou atenção especial com a estética do ambiente: "Eu particularmente achei muito interessante essa disposição da barra (uma única barra para lavatório e sanitário) porque fica uma coisa mais discreta. Pra um hóspede que não é deficiente, é menos assustador".

Figura 18. Grávida - Indicação do local onde deveriam estar as tolhas para secagem de mãos

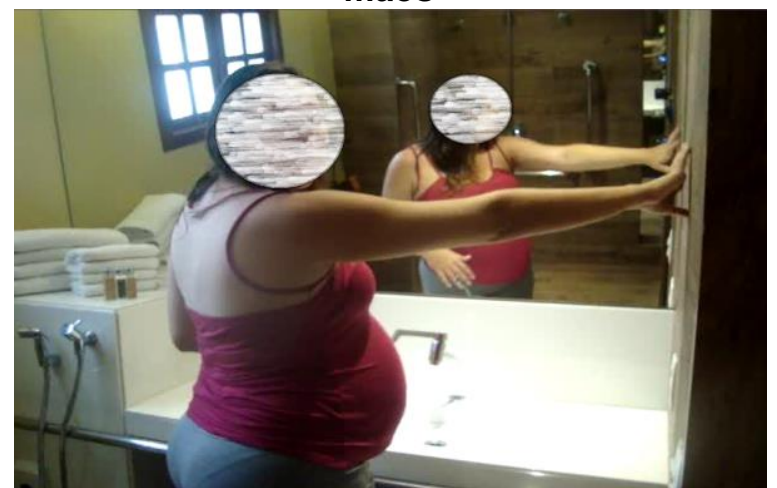

Fonte: Acervo próprio, 2015.
Figura 19. Grávida - Inexistência de divisória permite que a água do banho molhe todo $o$ banheiro

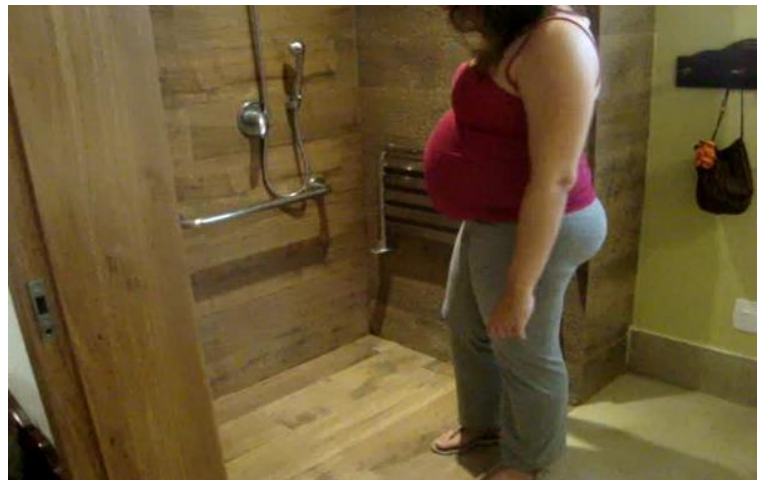

Fonte: Acervo próprio, 2015. 


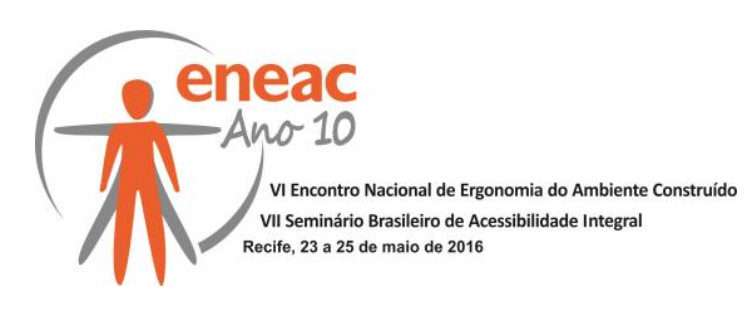

Os esquemas representativos das áreas percebidas como positivas e negativas pelos usuários no banheiro B se apresentam da seguinte maneira (Figura 20 a Figura 22):

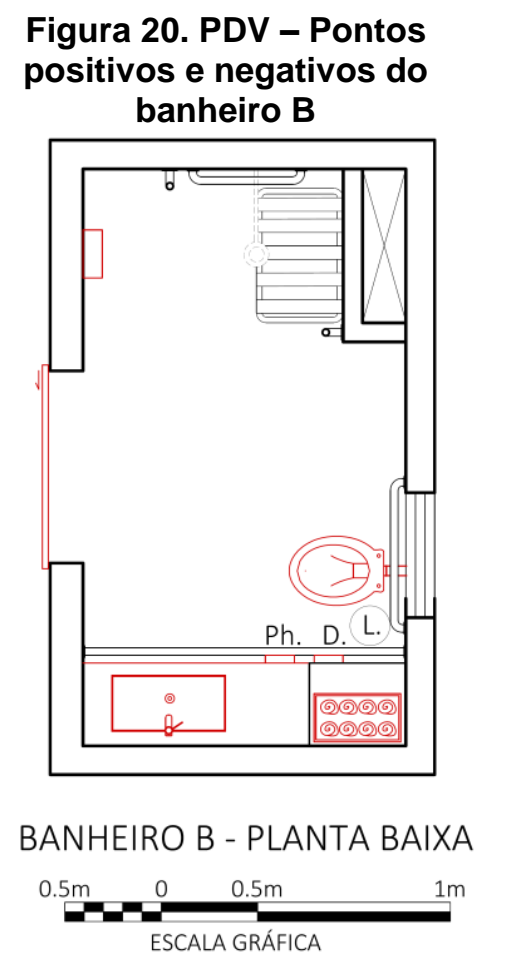

LEGENDA: PONTOS POSITIVOS / PONTOS NEGATIVO:LEG

Fonte: Produção da autora, 2015.
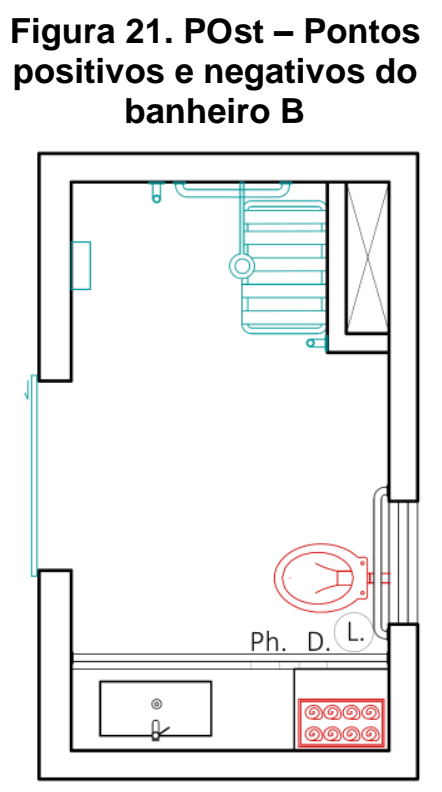

BANHEIRO B - PLANTA BAIXA

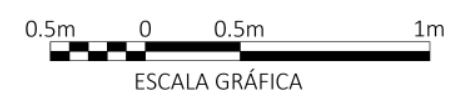

Fonte: Produção da autora, 2015.
Figura 22. Grávida - Pontos positivos e negativos do banheiro B

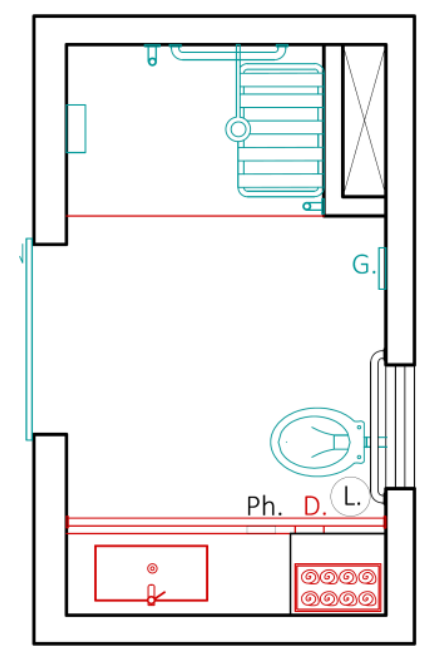

BANHEIRO B - PLANTA BAIXA

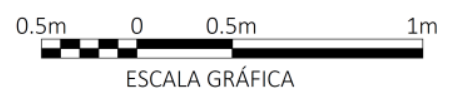

Fonte: Produção da autora, 2015.

\section{CONSIDERAÇÕES PARCIAIS}

Diante dos dados coletados com os três primeiros participantes, foi possível observar como problemas recorrentes:

- A indicação da altura da bacia sanitária regulamentada pela norma técnica como inferior ao mínimo necessário para utilização com conforto;

- A preferência dos usuários pela localização de barras e acessórios do lado direito por contribuir para a empunhadura mais firme e encontro imediato, condição que não é imposta pela norma, que permite a localização em ambos os lados;

- Dificuldade na utilização de comandos do tipo alavanca, recomendados pela norma;

- Problema ocasionado pela inexistência de desnível na área do boxe, pois durante o banho o restante do ambiente é molhado, o que pode ocasionar acidentes;

- Importância da oferta de ducha higiênica para higienização das bolsas coletoras de pessoas ostomizadas, apesar de não ser obrigatória por norma.

Diante dessas observações, até o momento tem-se a indicação de que os parâmetros da NBR 9050/04 não respondem integralmente às necessidades dos usuários de banheiros públicos. Porém, é necessário realizar as tarefas acompanhadas com os outros seis participantes a fim de confirmar ou não essa tendência de resposta à questão de pesquisa. 


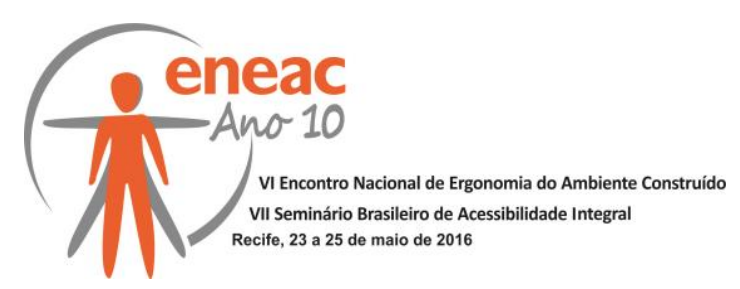

\section{REFERÊNCIAS BIBLIOGRÁFICAS}

ASSOCIAÇÃO BRASILEIRA DE NORMAS TÉCNICAS (ABNT). NBR 9050: Acessibilidade a edificações, mobiliário, espaços e equipamentos urbanos. Rio de Janeiro: 2004.

BRASIL. Decreto 5.296, de 02 de dezembro de 2004. Disponível em: <http://www.planalto.gov.br/ccivil_03/_ato2004-2006/2004/decreto/d5296.htm>. Acesso em: 02 jul. 2014.

BRASIL. Constituição (1988). Constituição da República Federativa do Brasil. Disponível em: <http://www.planalto.gov.br/ccivil_03/Constituicao/Constituicao.htm>. Acesso em: 03 fev. 2016.

DISCHINGER, M. Designing for all senses: Accessible spaces for visually impaired citizens. 2000. 260 f. Tese (Doutorado em Filosofia). School of Architecture, Chalmers University of Technology, Göteborg, Suécia.

RHEINGANTZ, P. A; AZEVEDO, G.; BRASILEIRO, A.; ALCANTARA, D.; QUEIROZ, M. Observando a qualidade do lugar: procedimentos para a avaliação pós-ocupação. Rio de Janeiro: UFRJ/PROARQ, $2009 . \quad$ Disponível em: <http://www.fau.ufrj.br/prolugar/arq_pdf/livros/obs_a_qua_lugar.pdf>. Acesso em: 24 nov. 2014.

STEINFELD, E; MAISEL, J. Universal Design: creating inclusive environments. New Jersey: John Wiley \& Sons, 2012. 